\title{
Performance Analysis of Spherical Stacked-Patch Antennas
}

\author{
UDK 621.396.677
}

IFAC 5.8.3

Original scientific paper

\begin{abstract}
Arrays of circular stacked-patch antennas, mounted in a multilayer spherical structure, are analyzed using the spectral-domain approach and the moment method. The interest for spherical arrays is based on their possibility to scan a single or multiple beams over the entire hemisphere. The influence of structure radius on input impedance, mutual coupling and radiation pattern is investigated. It is shown that the properties the most affected by the variation of structure radius are the resonant frequency and the mutual coupling level. The results confirm the importance of rigorous analysis of curved patch antennas. Furthermore, a laboratory model is built to validate the developed program. The agreement between measured and calculated results is good..
\end{abstract}

Key words: spherical patch antennas, conformal antennas, moment methods, antenna array mutual coupling

\section{METHOD OF ANALYSIS}

Spherical antenna arrays present a natural choice if complete hemispherical coverage with nearly constant beam width is needed. This makes them an optimal solution for satellite tracking, telemetry and command services applications, allowing simultaneous communication with multiple satellites from one base station $[1,2]$. As array element a circular patch antenna is proposed due to its thin profile, ability to conform the considered structure and good polarization properties [3]. The narrow bandwidth of a single patch antenna is widened by stacking a parasitic element above it.

We have developed a program that rigorously analyzes spherical arrays of circular stacked-patch antennas. The geometry of the problem is given in Figure 1. A circular stacked-patch is mounted in a multilayer spherical structure. The radii of the grounded sphere, the fed patch and the parasitic patch are $R_{\text {gnd }}, R_{\text {patch_l } 1}$ and $R_{\text {patch } 2}$, respectively. Therefore, the thicknesses of the first and the second dielectric layers are $h_{1}=R_{\text {patch } 1}-R_{\text {gnd }}$ and $h_{2}=R_{\text {patch_2 }}-R_{\text {patch } 1 \text { l }}$, respectively. The coordinates of the central patch are $0 \leq \theta \leq \theta_{\text {patch } i}$ and $-\pi \leq \phi \leq \pi\left(\theta_{\text {patch } i}\right.$ is defined as $\theta_{\text {patch } i}=r_{i} / R_{\text {patch } i}^{-}$, $i=1,2$ ). In other words, the center of the central patch is defined with $\theta=0^{\circ}$. In the case of an array, all patches have the same dimensions and their position can be obtained by rotating the cen-

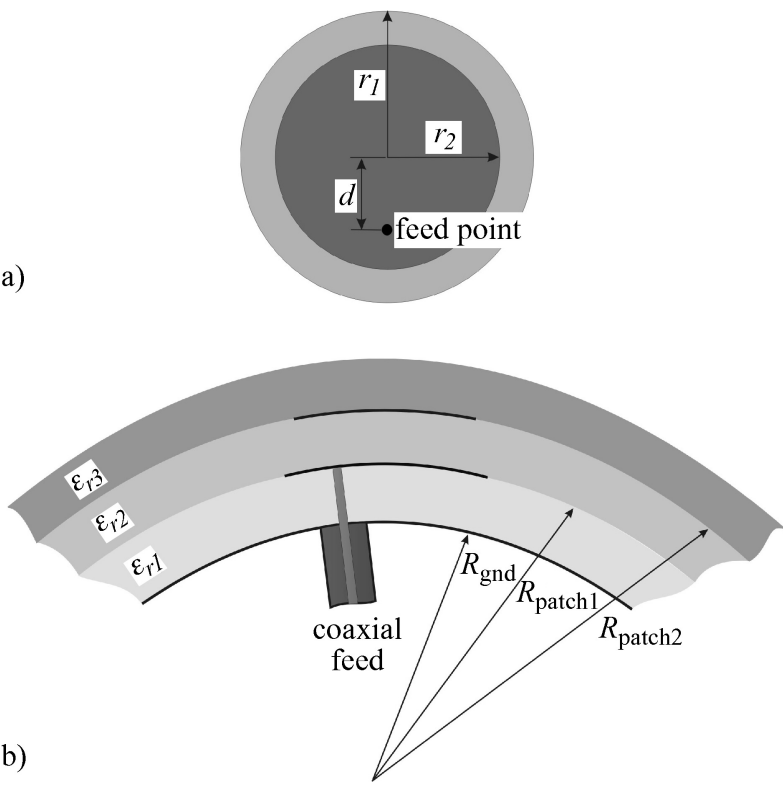

Fig. 1 The geometry of one circular stacked-patch antenna

tral patch around the sphere centre (notice that there is no simple expression for coordinates of the edge of a generally positioned patch). All the antennas are fed by a coaxial probe. The arc distance of the feeding point from the patch center is $d$. The probe feeding is preferred due to its compatibility with the topology of the microwave inte- 
grated circuits (MMICs) where the active part is placed below the grounded plane and the signals are transmitted to the antennas through the boundaries between layers via coaxial probes. Furthermore, from the patch antenna point of view, there is a large similarity between coaxial probe and the microstrip line feeding (current distribution, input impedance, radiation pattern) [4].

The analysis approach is based on solving the integral equation for the electric field, and on the moment method (MoM), where the elements of the MoM matrix are calculated in the spectral domain. The motivation for applying the spectral domain technique was to transform the three-dimensional problem into a spectrum of one-dimensional problems, which is much easier to solve $[5,6]$. Since the problem is defined in the spherical coordinate system, the spectrum is obtained by applying the vector-Legendre transformation to the patch current $[7,6]$. The Green's function of a general multilayer spherical structure is computed using the G1DMULT algorithm that calculates spectral domain Green's functions of general multilayer planar, circular cylindrical and spherical structures [6].

Direct implementation of the spectral-domain moment method is not possible for analyzing antennas mounted on a sphere of large radius because ratios of very large numbers need to be calculated. To find a numerically stable solution we have introduced normalized Legendre polynomials and an alternative definition of the vector-Legendre transformation. Furthermore, in order to analyze patch arrays on spherical structures, an efficient

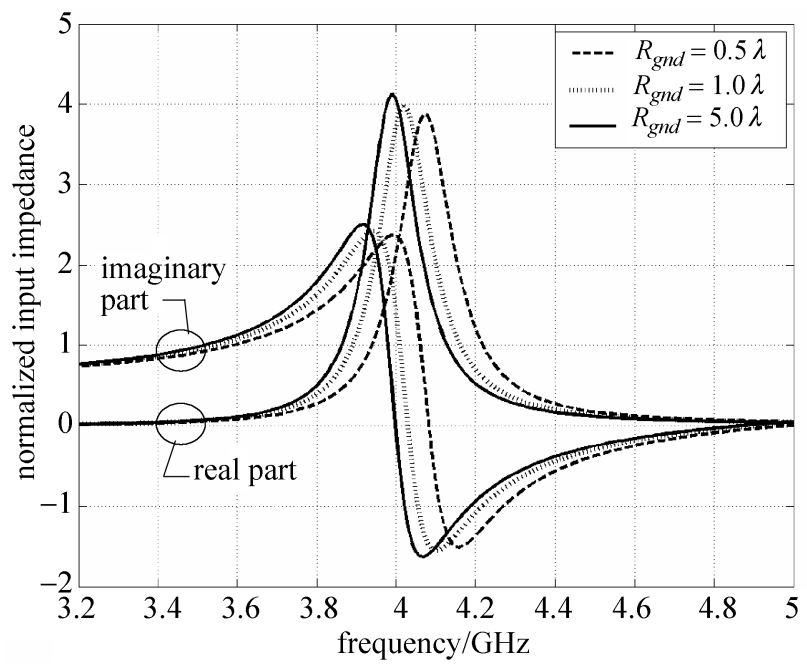

Fig. 2 Input impedance of a single patch antenna for different sphere radii way of calculating the vector-Legendre transforms of displaced basis and test functions has been investigated. We have established an analytic relationship between vector-Legendre transformations of basis/test functions defined on the central patch (with the centre at the pole, $\theta=0^{\circ}$ ) and on the patch located at an arbitrary position. In the first step, two auxiliary functions, $A^{J}$ and $\psi^{J}$, are defined in a manner similar to the representation of the electric field via vector and scalar potentials. Their definitions do not depend on the coordinate system, i.e. they are valid in both global and local coordinate systems. Moreover, their representations in different coordinate systems can be linked with help of the Vilenkin's addition theorem for spherical harmonics. More details about the developed analysis method can be found in [8] and [9].

\section{RESULTS}

The effects of the sphere size on the input impedance, mutual coupling and radiation pattern will be illustrated in the following examples. We consider a circular stacked-patch antenna that is embedded in a three-layer spherical structure (see Figure 1). First, in Figures 2-6, we consider a stacked-patch antenna with permittivity and thickness of each layer as follows: $\varepsilon_{r l}=2.45, h_{1}=1.52 \mathrm{~mm}$, $\varepsilon_{r 2}=1.22, h_{2}=6.352 \mathrm{~mm}, \varepsilon_{r 3}=2.45, h_{3}=0.761 \mathrm{~mm}$. The diameters of the lower and upper patch are $2.647 \mathrm{~cm}$ and $2.673 \mathrm{~cm}$, respectively. The lower patch is excited with a coaxial transmission line, and the excitation position is $0.794 \mathrm{~cm}$ relative to patch center.

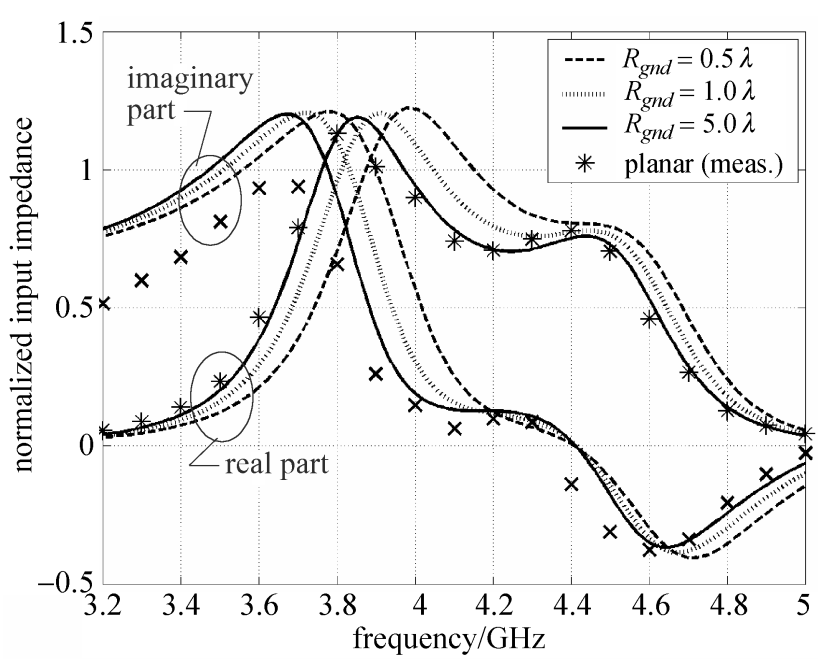

Fig. 3 Input impedance of a stacked-patch antenna for different sphere radii 


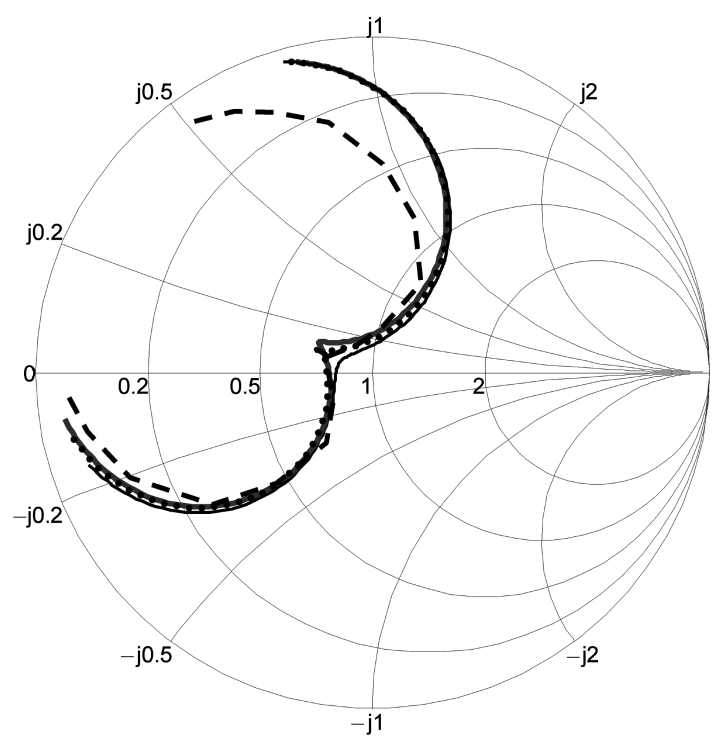

Fig. 4 Input impedance of a stacked-patch antenna for different sphere radii, $f=3.2-5.0 \mathrm{GHz}$

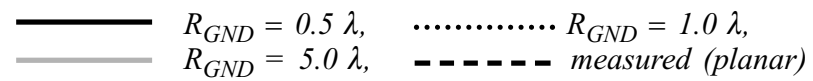

The influence of the sphere radius on input impedance of spherical single patch and stacked-patch antennas is shown in Figures 2-4. For comparison, the measured input impedance of a planar stacked-patch antenna with the same dimensions is also given in Figure 4. It can be seen that the sphere radius mostly influences the resonant frequency, i.e. the shape and the magnitude of the impedance curve is almost the same for all chosen radii of the structure $(0.5 \lambda-5.0 \lambda$ at $4.0 \mathrm{GHz})$. Therefore, it is almost impossible to distinguish impedance curves in the Smith chart. Notice that the shape of impedance loci of a stacked-patch antenna can be interpreted as a superposition of two impedance loci of single patch antennas, i.e. each patch of the stacked-patch antenna can be treated as a separate resonator.

The effect of the radius of the ground plane (grounded shell) on radiation pattern is given in Figure 5. For comparison, the calculated radiation pattern of a planar stacked-patch antenna with same dimensions is also given. The operating frequency is $4.5 \mathrm{GHz}$. It can be seen that when increasing the radius of the sphere the main lobe of the spherical patch antenna becomes narrower, approaching the main lobe of the planar counterpart, i.e. the main lobe is wider for spherical patch antennas, especially in the H-plane. As expected, the back-radiation is smaller for spheres with larger radii.
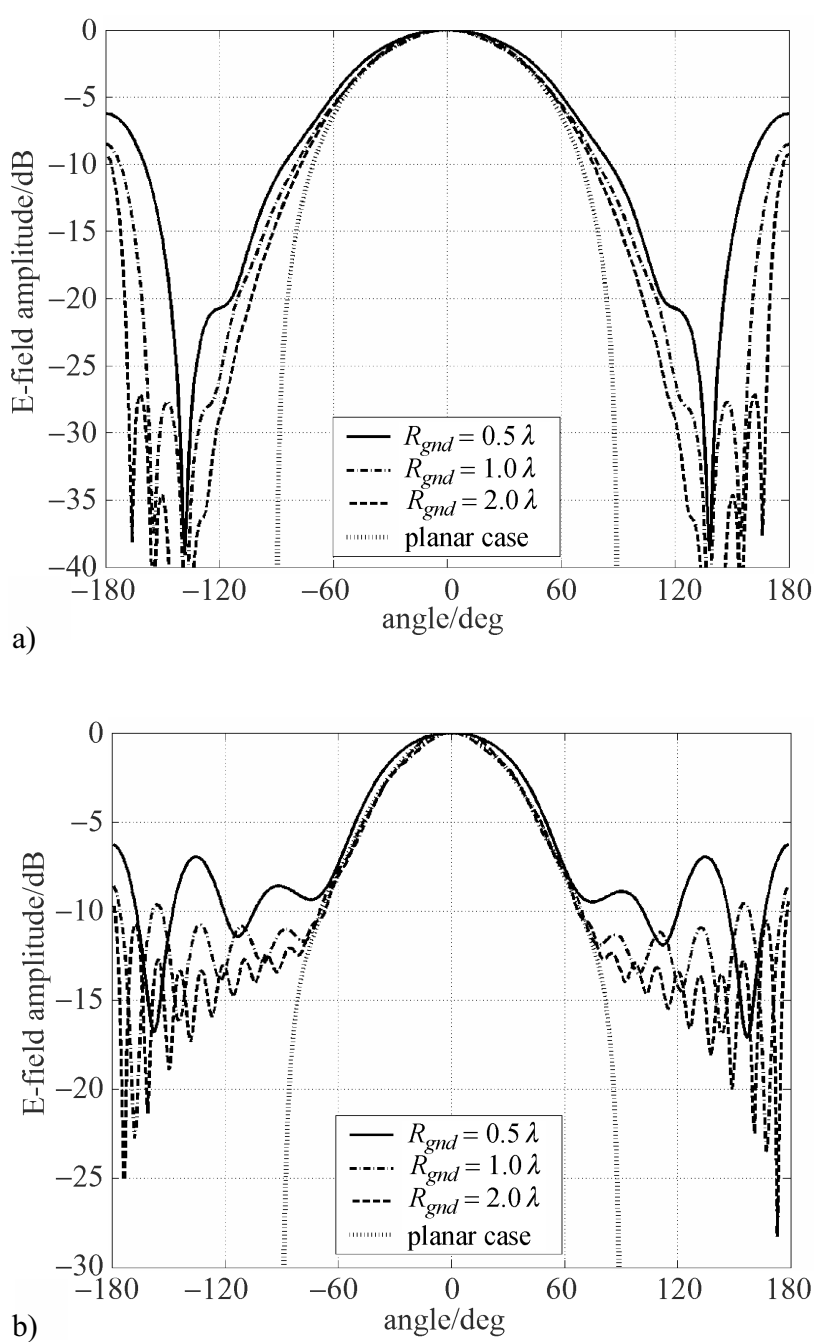

Fig. 5 Calculated radiation pattern of a spherical stacked-patch antenna for different sphere radii; a) H-plane, b) E-pla$n e ; f=4.5 \mathrm{GHz}$

The comparison of mutual coupling level of a two-patch array of single-patch and stacked-patch antennas is given in Figure 6. The radius of the grounded sphere is $15 \mathrm{~cm}(2.0 \lambda$ at $4.0 \mathrm{GHz})$, and the distance between patch centers is $12 \mathrm{~cm}(1.6 \lambda$ at $4.0 \mathrm{GHz}$ ). In order to match the single patch antenna, the position of the feed point is placed 0.4 $\mathrm{cm}$ relative to the patch center; other antenna dimensions are the same as before. Notice that from the shape of the magnitude of $S_{21}$ parameter it can be seen that the stacked-patches have wider bandwidth (which was the main motivation for their development). It is interesting to see that the coupling level in both E- and H-planes is higher for single patch antennas than for the stacked-patch antennas in the frequency band where the single patch antenna is matched. This result is not intu- 

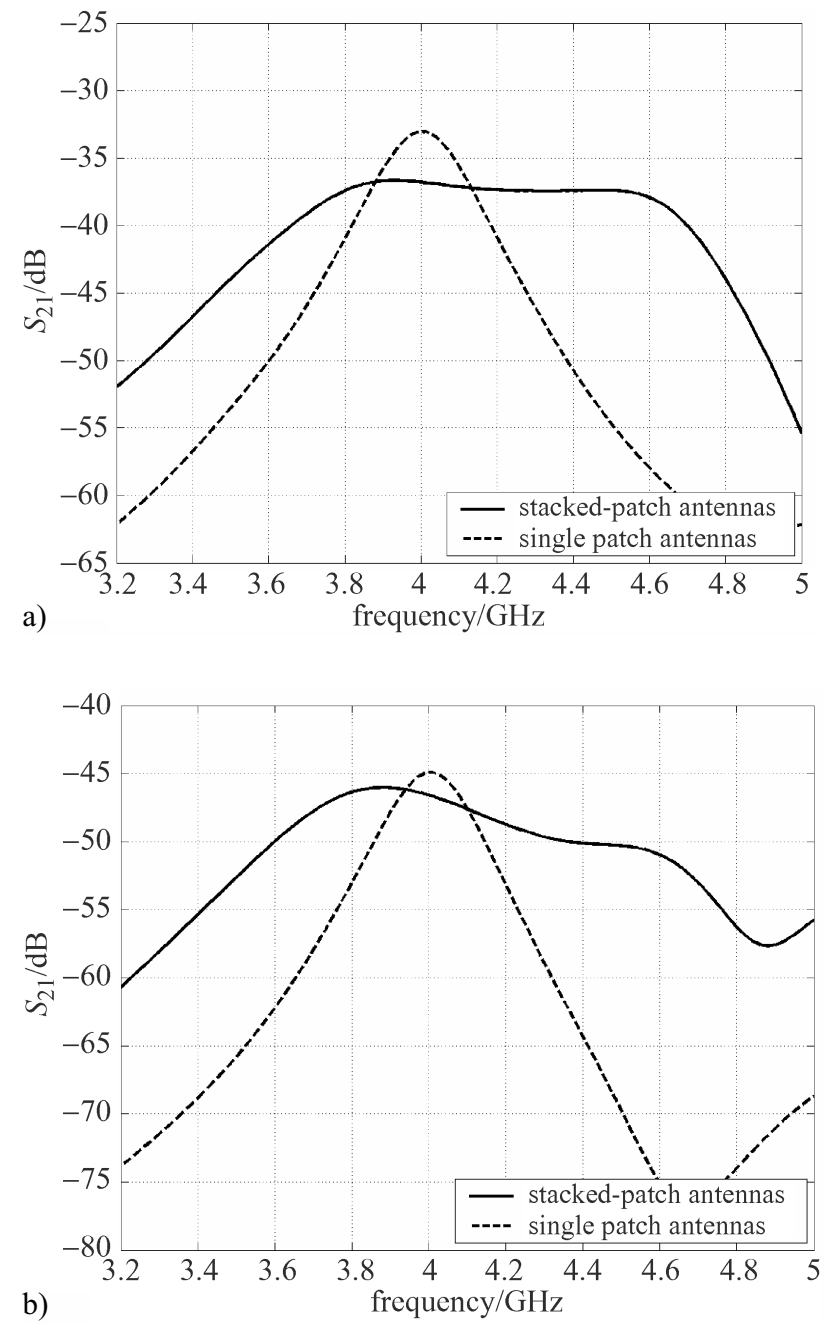

Fig. 6 Calculated magnitude of $S_{21}$ parameter of a two-patch array as a function of frequency; a) coupling in E-plane, b) coupling in H-plane

itive since one would expect that the stacked-patch antennas have stronger coupling because the coupling results from the interaction of 4 patches, whereas in the case of single patch configuration the coupling results from the interaction of 2 patches.

In the next example, the influence of the sphere radius on mutual coupling level is investigated (Figure 7). Since there are no available results for the coupling of circular stacked-patch antennas in the open scientific literature, we considered two single patches. The diameter of the patches is 1.86 $\mathrm{cm}$ and they are printed on a grounded dielectric layer with $\varepsilon_{r}=12.5$ and $h_{l}=0.16 \mathrm{~cm}$. The position of the feed point is $0.794 \mathrm{~cm}$ relative to the patch center. The magnitude of the $S_{21}$ parameter, both in E- and H-plane, is shown as a function of
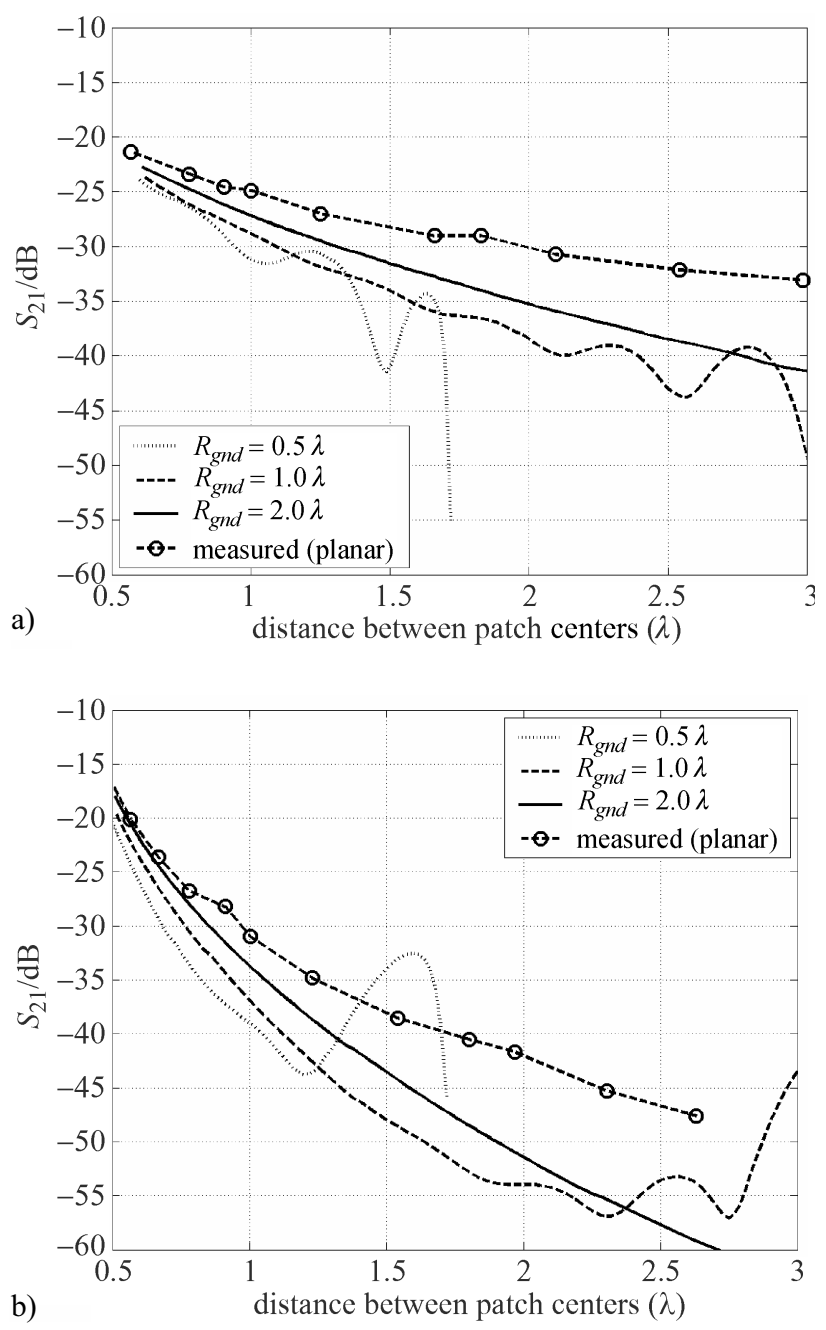

Fig. 7 Calculated magnitude of $S_{21}$ parameter of a two-patch array as a function of spacing between patch centers; a) E-plane coupling, b) H-plane coupling

spacing between patch centers (arc distance on the sphere surface at patch level). The coupling level is compared to the measured results of the equivalent planar case [10]. It can be seen that the coupling is weaker for the spherical case, compared to the planar one. For smaller structure radii mutual coupling starts to be oscillatory due to interference of forward and backward propagating waves around the sphere.

In order to validate the program, a laboratory model was developed where it is simple to measure different array configurations (Figure 8). The model was built from a copper sphere of radius $a=18.5 \mathrm{~cm}$ on which patches were mounted at different positions. Mounting of patches at arbitrary positions is very simple: one just needs to place an SMA connector at the desired position on 
a)

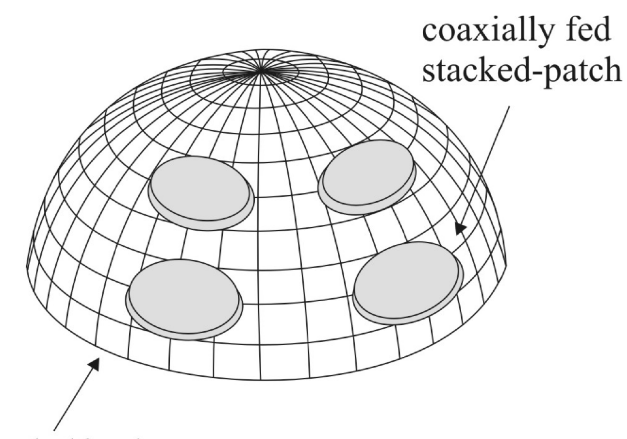

copper half-sphere

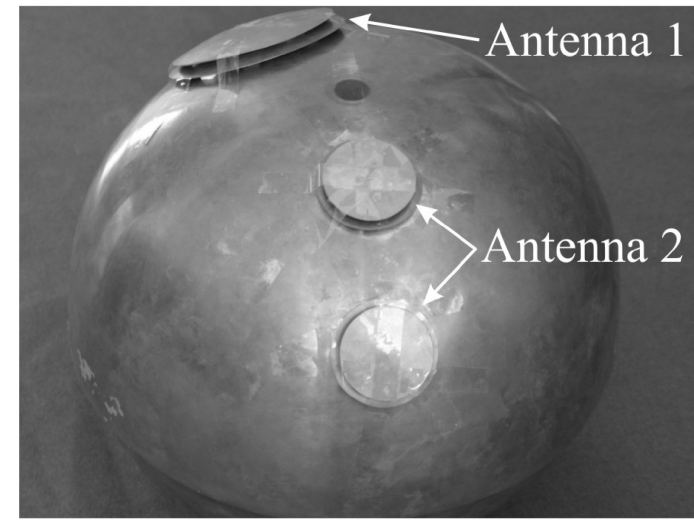

Fig. 8 Sketch a) and photo b) of the developed laboratory model

the grounded shell. Small Styrofoam cubes $\left(\varepsilon_{r} \approx\right.$ $\approx 1.0$ ) are used as spacers between patches and the grounded shell. Note that the patches are made from a sphere of appropriate radius since it is important that patches follow the spherical structure. Experimental spherical patch and stacked-patch antennas of two different sizes were built. The goal was to test the program for different angular dimensions of the patch, i.e. the diameter of the larger patch is $36.7 \mathrm{deg}(12.2 \mathrm{~cm})$, whereas the diameter of the smaller patch is $18.7 \mathrm{deg}(6.2 \mathrm{~cm})$. The dimensions of the developed patch antennas are given in Table 1.

The comparison of calculated and measured input impedance of the developed spherical stacked-patch antennas is given in Figures 9 and 10.
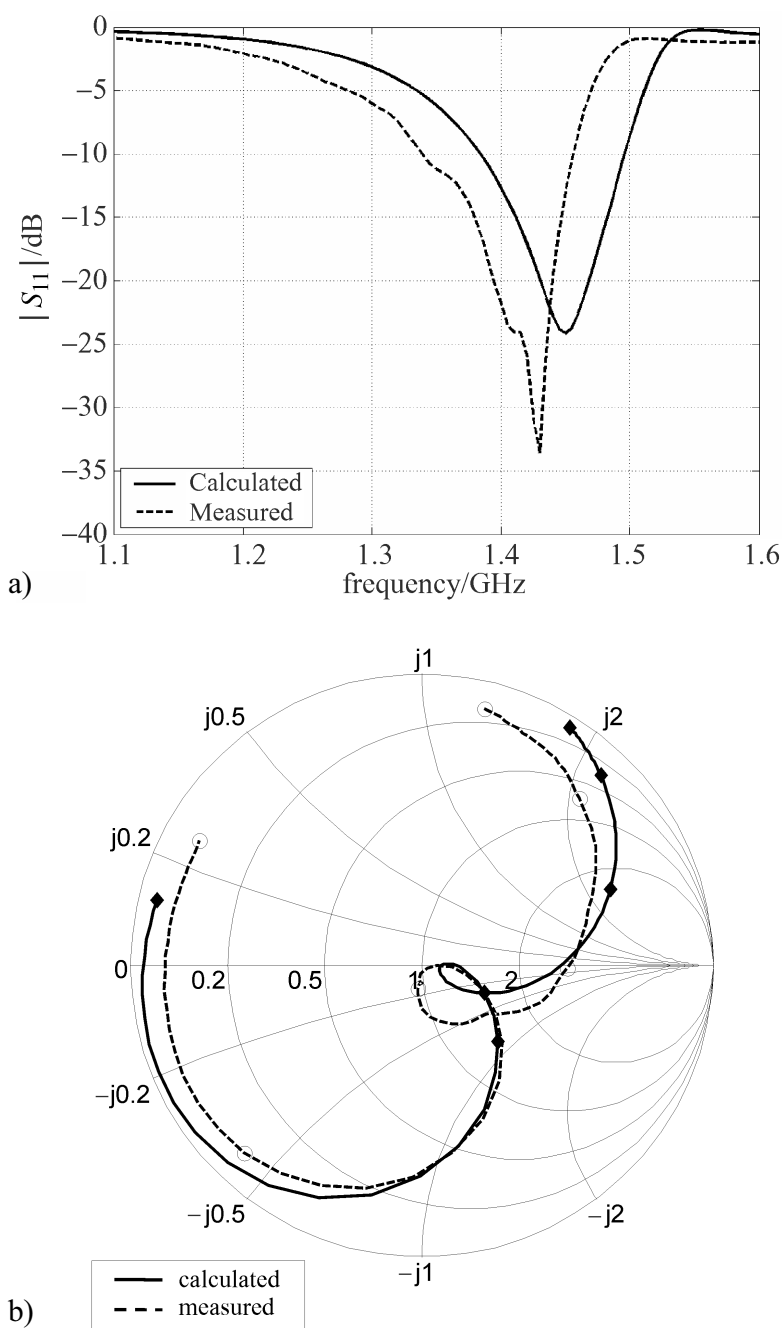

Fig. 9 Comparison of calculated and measured input impedance of the stacked-patch antenna 1 (dimensions are given in Table 1): a) $\left|S_{11}\right|$ representation, b) Smith chart representation $(\Delta f=0.1 \mathrm{GHz})$

Both the representation in the Smith chart and the magnitude of the $S_{11}$ parameter are plotted. The difference between the calculated and measured resonant frequency can be attributed to the imperfections in the test prototype. In particular, it is hard to make patches with the proper curvature since each patch should be cut from a curved cop-

Table 1 The dimensions of the experimental spherical patch antenna

\begin{tabular}{|c|c|c|c|c|}
\hline Antenna \# & $\begin{array}{c}\text { Patch diameters } \\
\left(r_{k}, k=1,2\right)\end{array}$ & Angular width & $\begin{array}{c}\text { Thickness } \\
\left(h_{k}, k=1,2\right)\end{array}$ & $\begin{array}{c}\text { Feed point } \\
\text { (relative to the patch center) }\end{array}$ \\
\hline \multirow{2}{*}{1} & $\begin{array}{l}12.2 \mathrm{~cm} \\
10.8 \mathrm{~cm}\end{array}$ & $36.7 \mathrm{deg}$ & $\begin{array}{l}0.55 \mathrm{~cm} \\
0.55 \mathrm{~cm}\end{array}$ & $5.15 \mathrm{~cm}$ \\
\hline 2 & $6.2 \mathrm{~cm}$ & $18.7 \mathrm{deg}$ & $\begin{array}{l}0.52 \mathrm{~cm} \\
0.52 \mathrm{~cm}\end{array}$ & $2.0 \mathrm{~cm}$ \\
\hline
\end{tabular}



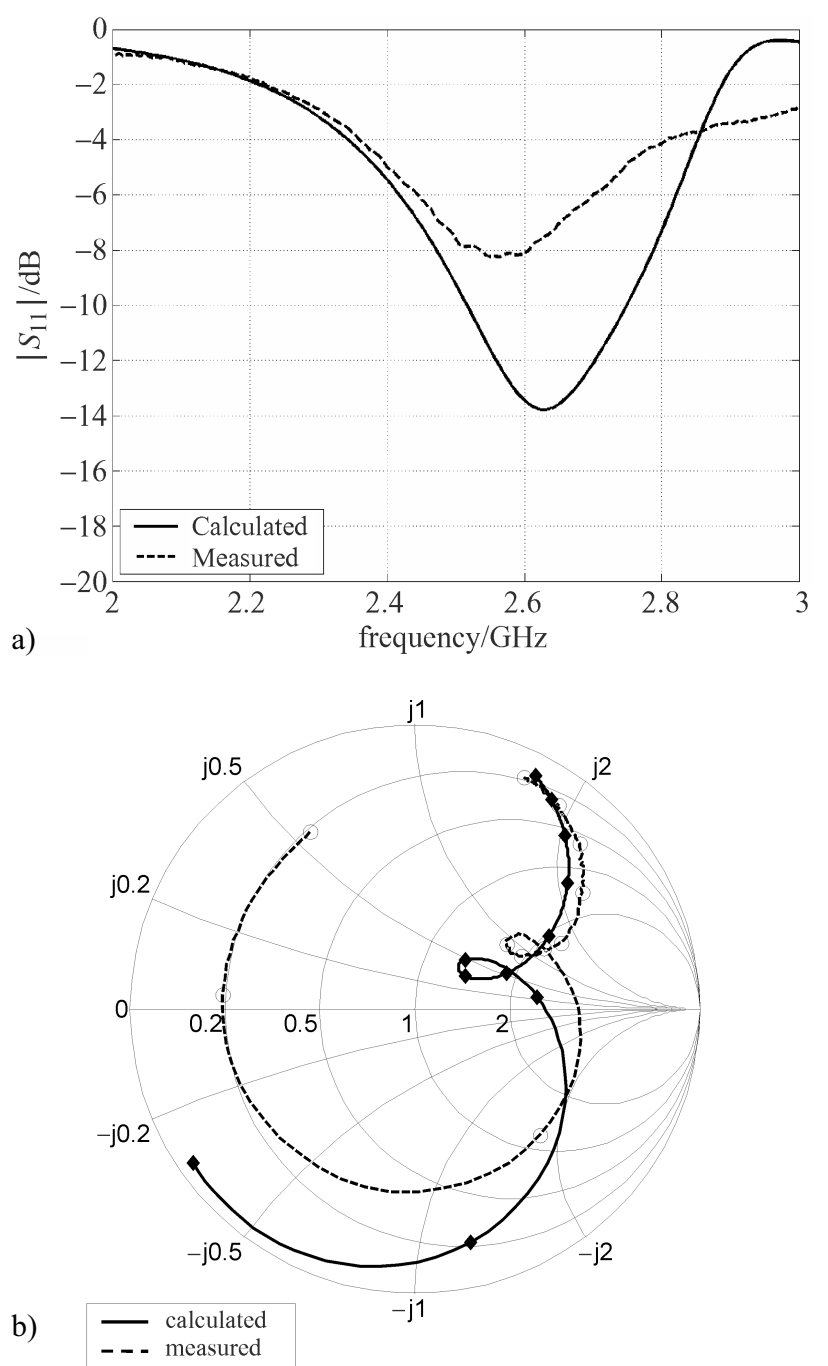

Fig. 10 Comparison of calculated and measured input impedance of the stacked-patch antenna 2 (dimensions are given in table 1): a) $\left|S_{11}\right|$ representation, b) Smith chart representation $(\Delta f=0.1 \mathrm{GHz})$

per plate with a slightly different radius of curvature. When mounting the patches on the grounded sphere we noticed a large sensitivity of resonant frequency on deviation from the spherical symmetry, depending on whether the curvature of the patch is smaller or larger than required. The shift of the resonant frequency can be approximately determined using the perturbational method $[5,8]$, i.e. the resonant frequency is directly influenced by the electric and magnetic energies yielded or removed from the cavity:

$$
\frac{\omega-\omega_{0}}{\omega_{0}} \approx \frac{\iiint_{\Delta V}\left(\mu\left|\mathbf{H}_{0}\right|^{2}-\varepsilon\left|\mathbf{E}_{0}\right|^{2}\right) \mathrm{d} V}{\iiint_{V}\left(\mu\left|\mathbf{H}_{0}\right|^{2}+\varepsilon\left|\mathbf{E}_{0}\right|^{2}\right) \mathrm{d} V} .
$$

Here $\Delta V$ represents the volume removed from the resonator, and the $\mathbf{E}_{0}$ and $\mathbf{H}_{0}$ are the electromagnetic field distribution of the unperturbed cavity. For example, if the curvature of the patch is smaller than the one that follows the spherical symmetry, the resonant frequency is higher since we have "removed " the volume from the centre of the patch where the magnetic energy has a maximum (and the electric energy has a minimum). The opposite situation occurs if the curvature of the patch is too large. In [8] it is reported that a $2.7 \%$ change in the curvature of a rectangular spherical patch will cause a shifting of the resonant frequency of around $3.5 \%$.

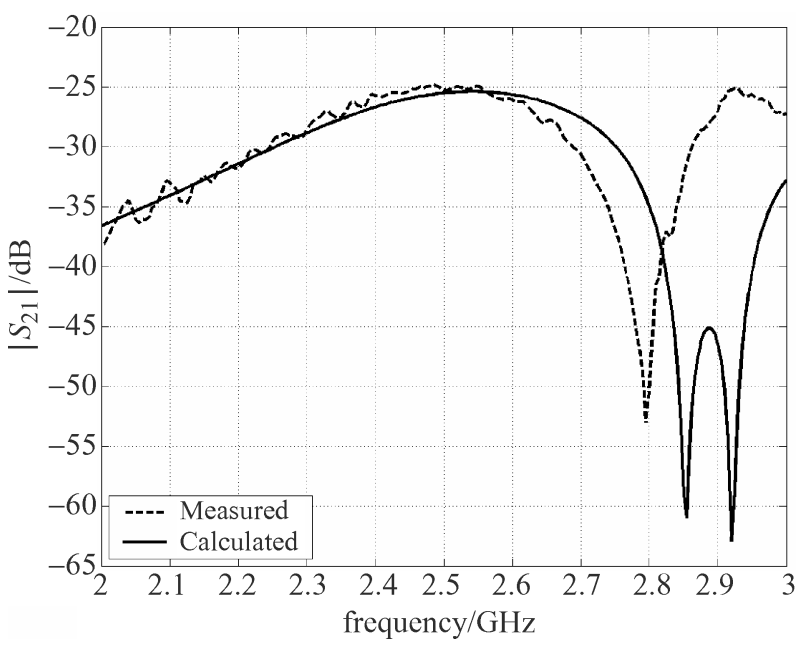

Fig. 11 Calculated and measured magnitude of $S_{21}$ parameter of a two-patch array

The comparison of measured and calculated mutual coupling level in E-plane is shown in Figure 11. A two-patch array of smaller stacked-patch antennas (see table 1 for dimensions) was built with the distance between patch centres equal to $10.25 \mathrm{~cm}$ (arc distance on the sphere surface at the driven patch level). The agreement between the results is good, except for the frequency shift. Note that both the calculated and measured results have a deep low-coupling region just above the higher resonant frequency of the stacked-patch antenna. This is due to the relative phase of the currents on the fed and parasitic patch. In more details, there is a 180 degrees difference between the current phases for frequencies just above the higher resonant frequency (the resonant frequencies of the lower and upper patch resonators are shifted in order to achieve larger frequency bandwidth), and therefore the fields radiated by these two patches almost cancel out in the plane parallel to the patches. 


\section{CONCLUSIONS}

The paper presents the properties of stacked-patch antennas mounted on spherical structures. In the analysis, spherical arrays are often approximated with a corresponding planar structure, and the spherical geometry is later accounted for by an appropriate coordinate and phase transformation. However, in many practical applications one cannot neglect the structure curvature. This is particularly important when accounting for the mutual coupling effects, since the magnitudes of mutual coupling coefficients depend strongly on the curvature. Mutual coupling can drastically change the embedded element pattern of each antenna element, and has to be rigorously included in the analysis procedure. Therefore, we have developed a program that rigorously analyzes arrays of circular stacked-patch antennas embedded in a spherical multilayer structure. The considered examples show that the largest difference between the planar and spherical patch arrays are in the mutual coupling level and in the resonant frequency of the antenna element. The radiation patterns of antenna elements mostly differ in the backside radiation level and to some extent in the width of the main lobe.

Since there are only a few measured results of spherical patch antennas in open literature, we have built a laboratory model to test properties of different patch configurations and to validate the accuracy of the developed program. Measurements show a large sensitivity of the resonant frequency on deviations from the spherical symmetry and on the radius of the structure. Otherwise, the agreement between calculated and measured results is good.

\section{ACKNOWLEDGEMENT}

This material is based upon work supported by the European Office of Aerospace Research and Development, Air Force Office of Scientific Research, Airforce Research Laboratory, under Contract No. FA8655-04-1-3050.

\section{REFERENCES}

[1] B. Tomasic, J. Turtle, S. Liu, A Geodesic Sphere Phased Array for Satellite Control and Communication. International Union of Radio Science, XXVII ${ }^{\text {th }}$ General Assembly, Maastricht, The Netherlands, August 2002.

[2] B. Tomasic, J. Turtle, S. Liu, Spherical Arrays Design Considerations. Proceedings of $18^{\text {th }}$ International Conference on Applied Electromagnetics and Communications, (ICECOM'05), Dubrovnik, Croatia, 2005, 487-493.

[3] J. R. James, P. S. Hall, (eds.): Handbook of Microstrip Antennas. (Peter Peregrinus, London, 1988).

[4] Z. Sipus, J. Bartolic, B. Stipetic, Input Impedance of Rectangular Patch Antenna Fed by Microstrip Line. Electronics Letters, Vol. 28, No. 20, pp. 18861888, Sep. 1992. Errata, Electronics Letters, Vol. 28, No. 23, p. 2199, Nov. 1992.

[5] R. F. Harrington, Time-Harmonic Electro-Magnetic Waves. McGraw-Hill, 1961.

[6] Z. Sipus, P.-S. Kildal, R. Leijon, M. Johansson, An Algorithm for Calculating Green's Functions for Planar, Circular Cylindrical and Spherical Multilayer Substrates. Applied Computational Electromagnetics Society Journal, Vol. 13, No. 3., pp. 243-254, Nov. 1998.

[7] W. Y. Tam, K. M. Luk, Resonances in Spherical-Circular Microstrip Structures of Cylindrical-Rectangular and Wraparound Microstrip Antennas. IEEE Trans. Microwave Theory Tech.., Vol. 39, 1991, pp. 700-704.

[8] Z. Sipus, N. Burum, S. Skokic, P.-S. Kildal, Analysis of Spherical Arrays of Microstrip Antennas Using Moment Method in Spectral Domain. IEE Proceedings - Microwaves, Antennas and Propagation, Vol. 153, pp. 533-543, Dec. 2006.

[9] Z. Sipus, S. Skokic, Application of Vilenkin's Additional Theorem in the Analysis of Spherical Antennas and Periodic Structures. Proceedings of the European Conference on Antennas and Propagation, Nice, France, 2006, paper 363810zs in CD.

[10] M. D. Deshpande, M. C. Bailey, Analysis of Finite Arrays of Circular Microstrip Patches. IEEE Transaction on Antennas and Propagation., Vol. 37, pp. 1355-1360, Nov. 1989. 
Analiza svojstava sfernih mikrotrakastih antena s parazitskim rezonatorom. Zanimanje za sferne antenske nizove zasnovano je na njihovoj mogućnosti da usmjeravaju jednu ili više glavnih latica preko cijelog prostora. U ovom članku razmatrane su kružne mikrotrakaste antene s parazitskim rezonatorom ugrađene $u$ općenitu višeslojnu sfernu strukturu. Postupak analize se temelji na metodi momenata u spektralnoj domeni. Razmatran je utjecaj zakrivljenosti strukture na ulaznu impedanciju, spregu između antenskih elemenata i dijagram zračenja. Pokazano je da promjena zakrivljenosti strukture najviše utječe na rezonantnu frekvenciju i na jačinu sprege između elemenata antenskog niza. Rezultati potvrđuju važnost rigorozne analize zakrivljenih mikrotrakastih antena. Nadalje, da bi se provjerili rezultati dobiveni razvijenim računalnim programom, izrađen je laboratorijski model sfernog antenskog niza. Ostvareno je dobro podudaranje izračunatih i izmjerenih rezultata.

Ključne riječi: sferne mikrotrakaste antene, konformne antene, metoda momenata, sprega između antenskih elemenata

\author{
AUTHORS' ADDRESSES \\ Zvonimir Šipuš, Siniša Škokić \\ University of Zagreb \\ Faculty of Electrical Engineering and Computing \\ Unska 3, HR-10000 Zagreb \\ Croatia \\ Nikša Burum \\ University of Dubrovnik \\ Ćira Carića 4, HR-20000 Dubrovnik \\ Croatia \\ e-mail: zvonimir.sipus@fer.hr, \\ sinisa.skokic@fer.hr, \\ niksa.burum@unidu.hr
}

Received: 2007-02-15 